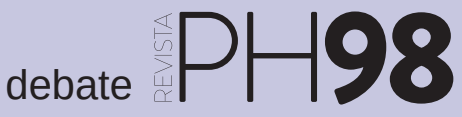

a debate ¿Hay patrimonio sin comunidad? Despoblamiento, turistificación y patrimonio cultural

| coordina Jaime Jover Báez

\title{
¿Para qué estamos conservando? Patrimonio, despoblamiento y turistificación
}

M. ${ }^{a}$ Carmen Reimóndez Becerra | grupo HUM 700, Patrimonio y desarrollo urbano y territorial en Andalucía, U. de Sevilla

URL de la contribución <www.iaph.es/revistaph/index.php/revistaph/article/view/4502>

El despoblamiento de los pueblos ha sido un problema que se viene desarrollando desde la revolución industrial. Estos enclaves, con una economía basada principalmente en el sector primario, no son capaces de resistir, con una alta tasa de paro que provoca el exilio de los más jóvenes. Esto conduce a una escasez de habitantes que sólo hace más acuciante la situación, terminando por minar también los pocos servicios de los que disponen estas poblaciones.

Una dinámica parecida sucede en los centros históricos, que son abandonados para instalarse en las afueras, donde hay amplios espacios para dotar urbanizaciones con piscinas, garajes y espacios lúdicos privados, en concreto unos servicios con los que no puede competir

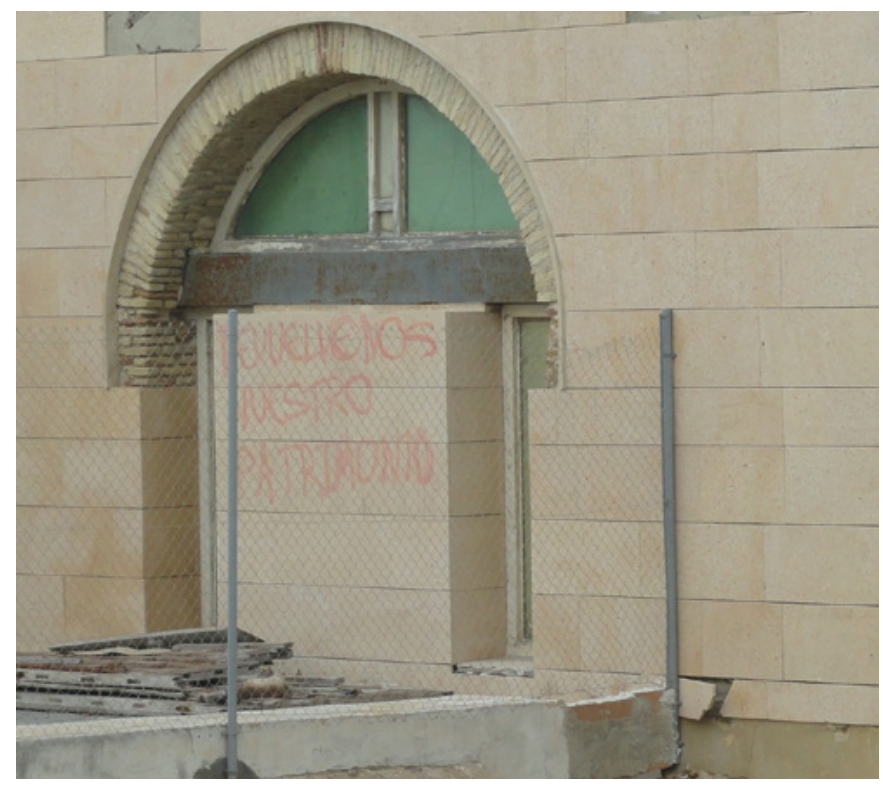

"Devuélvenos nuestro patrimonio", pintada en el teatro romano de Cádiz que denota el sentimiento de pérdida que sufre la comunidad un centro que cada vez está más devastado acuciado por la instalación de los grandes centros comerciales y de ocio en las periferias, produciéndose la gentrificación de la zona y la consecuente ruina del privilegiado patrimonio histórico-cultural del que disponen nuestras ciudades.

En ambos casos, la puesta en valor del patrimonio se instaura como un recurso más que útil para mantener la poca población que queda. El patrimonio se utiliza como reclamo para atraer gente del exterior de dichas comunidades. Visitantes, consumidores de cultura en su tiempo libre o que, simplemente, quieren elegir un lugar tranquilo donde vivir el resto de su vida, preferiblemente tradicional, por el auge que ha tomado todo lo ecológico en los últimos tiempos. Este flujo de personas requiere ser-

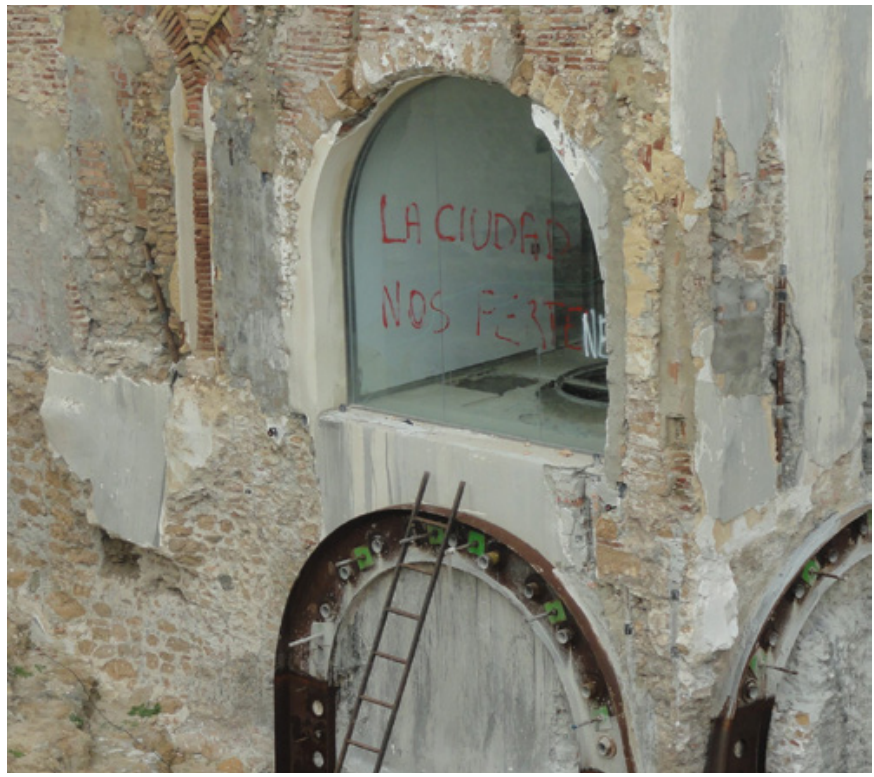

"La ciudad nos pertenece", pintada en el centro de interpretación del teatro romano de Cádiz, durante su rehabilitación (2017) | fotos M. ${ }^{a}$ Carmen Reimóndez 
a debate ¿Hay patrimonio sin comunidad? Despoblamiento, turistificación y patrimonio cultural

| coordina Jaime Jover Báez

vicios que los lugareños ven como el último recurso para poder sobrevivir en sus comunidades de origen.

La idea del patrimonio como motor de desarrollo ha quedado ampliamente demostrada en numerosos ejemplos y así está impresa en la memoria social. Gran parte de la población reconoce este valor (IBÁÑEZ, 2014). Incluso en los últimos años, es raro el programa político que no haga alguna alusión a las intenciones del partido con el patrimonio histórico. La puesta en valor se erige como el mejor invento para la atracción turística y la milagrosa recuperación económica de un destino.

Sin embargo, los resultados son tan variados como complejos. Conocemos casos exitosos económicamente, otros sin grandes recompensas y algunos que han aliviado la precariedad rural por algún periodo de tiempo. Ejemplos que han reforzado la identidad de sus ciudadanos y otros que han sido excusas para invertir en ayudas sociales, conllevando incluso el deterioro del objeto patrimonial en cuestión. No obstante, en la mayoría de los casos, la afluencia masiva o la llegada constante de gente foránea ha supuesto un crecimiento del municipio, muchas veces engañoso, que ha distorsionado sin remedio el urbanismo y el paisaje cultural de dichos pueblos. Asimismo, la ocupación de población extranjera en algunos municipios es tal que llega a constituirse en una nueva repoblación de estos núcleos que terminan siendo irreconocibles.

En el caso de los centros históricos, la situación es parecida. La solución más utilizada es escoger bienes patrimoniales estrella, materiales o inmateriales, que atraigan a turistas, aunque ello implique la desaparición de la vida tradicional de dichos enclaves. Casos como Barcelona, Sevilla y otras muchas ciudades sufren las consecuencias de ello: sus calles quedan tomadas por oleadas de turistas, por las que literalmente no se puede ni pasar, cambiando incluso la dinámica urbanística; sube la renta de los alquileres y los lugareños se ven obligados a trasladarse a zonas más alejadas, por lo que al final el beneficio económico de unos pocos se traduce en graves restricciones para la población local.
Si ampliamos perspectiva, se advierte una radicalización de las posturas. Mientras el interés por la conservación y puesta en valor del patrimonio crece, también lo hace la turismofobia en la sociedad que debía ser beneficiaria de dicho patrimonio. La puesta en valor se ha convertido en un arma de doble filo que debemos atender con premura antes que la situación sea incontrolable.

Si pretendemos adelantar cuestiones de futuro, podemos intuir que no existen modelos que ofrezcan garantías (PRATS, 2003), un mismo proyecto puede tener implicaciones muy diferentes en función del contexto físico y social-político en que se aplique. Asimismo, se puede advertir que cualquier intervención en patrimonio devuelve la inversión realizada multiplicada varias veces, y desencadena un movimiento transversal en muchos otros ámbitos, cuyas repercusiones aún no han sido analizadas convenientemente (REIMÓNDEZ, 2018).

La realidad es que no existen estudios sobre la gestión que estamos haciendo del patrimonio a pesar de que algunos autores han advertido que dicha gestión puede ser el mayor peligro para su futuro (QUEROL, 2010; FERNÁNDEZ CACHO, 2008).

En estos treinta años de gestión patrimonial ${ }^{1}$, desde que surgió la ley 16/85 de PHE, y se derivó sus competencias a las autonomías, ha ido encaminada a lo más urgente, la protección de un patrimonio avocado a desaparecer. Sin embargo, la conservación ha quedado relegada a segundo plano, desarrollándose principalmente en el tema de los bienes muebles, sin que se haya ocupado de estas cuestiones de puesta en valor. No existen protocolos o método establecido sobre cómo hacerlo de forma asertiva y mucho menos que garantice que se está utilizando el verdadero potencial que el patrimonio nos ofrece. La integración del patrimonio es un tema pendiente a pesar de ser de gran interés a nivel internacional según el Plan de conservación preventiva (PLAN, 2011).

Cuestiones como para qué conservar sólo se han comenzado a plantear en el Convenio de Faro (CONVENIO, 
2005). Sin embargo, cuando a hablamos de conservación de nuestro patrimonio rural o urbano, todos pensamos en volver a sentir las experiencias que teníamos de pequeños cuando íbamos allí, disfrutar de la tranquilidad de sus calles, de la familiaridad de los vecinos, de la pequeña fuente que reinaba en el caserío imbuido en la dinámica social propia de estos lugares, donde aún se respiraba una cultura propia, en definitiva una vida de verdad. Podemos seguir conservando piedras, escenarios, que hay que reconocer que podían haber desaparecido si no fuera por algunas de estas intervenciones, pero... ¿nos conformaremos con eso? ¿o queremos más? Esa es la cuestión que debemos responder.

\section{NOTA}

1. Sin menosprecio de la ley de Patrimonio Histórico Español de 1933 y la legislación anterior, consideramos que el sistema de gestión de patrimonio actual tiene sus orígenes en los años ochenta, cuando se introduce el concepto de patrimonio aceptado internacionalmente y se constituyen las bases administrativas que perduran hasta nuestros días.

\section{BIBLIOGRAFÍA}

- CONVENIO Marco del Consejo de Europa sobre el Valor del Patrimonio Cultural para la sociedad (2005) [en línea] Celebrado en Faro, 27 de octubre de 2005. Serie de Tratados del Consejo de Europa, n. ${ }^{\circ} 199$. Disponible en: <https://rm.coe. int/16806a18d3> [Consulta: 14/07/2019]

- IBÁÑEZ ALFONSO, M. (2014) Percepción y usos del patrimonio arqueológico de Sevilla. Sevilla: Secretariado de publicaciones de la Universidad de Sevilla, 2014

- FERNÁNDEZ CACHO, S. (2008) Patrimonio Arqueológico y planificación territorial. Sevilla: Consejería de Cultura, 2008

- PLAN Nacional de Conservación Preventiva. Consejo de Patrimonio Histórico celebrado en Burgos, marzo de 2011. Disponible en: <http://www.culturaydeporte.gob. es/planes-nacionales/dam/jcr:30080f76-742a-407a-a5aa1696b79f25ae/10-maquetado-conservacion-preventiva.pdf> [Consulta: 12/07/2019]

- PRATS, LL. (2003) Patrimonio+turismo= ¿desarrollo? Pa sos, revista de turismo y patrimonio cultural [en línea], vol. 1, n. ${ }^{\circ}$ 2, 2003, pp. 127-36 <http://www. pasosonline.org/ Publicados/1203/PS000603.pdf> [Consulta: 12/07/2019]

- QUEROL FERNÁNDEZ, M. A. (2010) Manual de Gestión del Patrimonio Cultural. Madrid: Ediciones Akal, 2010

- REIMÓNDEZ BECERRA. M. C. (2018) Veinte años de una intervención en Benaocaz. Aportaciones para una conservación preventiva contrastada. En Actas del VI Congreso Grupo Español de Conservación del IIC. ¿Y después? Control y mantenimiento del patrimonio cultural. Una opción sostenible. Vitoria Gasteiz, 20-22 de septiembre de 2018 [en línea] <https:// www.congreso2018.ge-iic.com/es/programa-preliminar/ actas/> [Consulta: 12/07/2019] 